\title{
Fixed Investments and Capital Flows: A Real Options Approach
}

\author{
Jorge A. Chan-Lau and Peter B. Clark \\ International Monetary Fund
}

\begin{abstract}
This paper draws a link between international capital flows and the real options approach to investment by extending the development and cascade model applied by Grenadier (Journal of Finance 51, 1996) to real estate markets. This modified model rationalizes such phenomena as gradual investment, investment booms, and investment during recessions, and it emphasizes the role of sunk costs and uncertainty in determining the timing of investment. We also show that the correlation between capital flows and the spread between the domestic return to capital and the foreign interest rate depends importantly on the source of uncertainty; if the foreign interest rate is stochastic, the correlation is expected to be high, but would be low if the uncertainty affects the domestic rate of return.
\end{abstract}

- JEL classification: F21, F32, F39

- Keywords: Fixed investments, Capital flows, Real options

\section{Introduction}

International capital flows often appear to be subject to sudden changes in sentiment. This is most clearly the case in episodes of speculative attacks against fixed or quasi-pegged exchange rates, such as occurred in the ERM in 1992-93, Mexico in 1994-95, and in many Asian emerging markets in 1997-98. Much of the analysis of episodes of this kind identifies shifts in economic fundamentals or self-fulfilling speculative bubbles as underlying the change in sentiment generating the fluctua-

\footnotetext{
*Corresponding address: Jorge A. Chan-Lau, International Monetary Fund, $70019^{\text {th }}$ St NW, Washington, DC 20431, Phone: (202) 623-4271; Fax: (202) 589-4271, E-mail: jchanlau@imf.org, Peter B. Clark, 5503 Montgomery St, Chevy Chase, MD 20815, U.S.A. Tel: (301) 662-0528, E-mail: pbclark2004@ comcast.net (C2006-Center for International Economics, Sejong Institution, All Rights Reserved.
} 
tions in capital flows. However, another perspective on the episodic nature of the movement of capital internationally can be obtained by looking at the factors underlying the timing of domestic investment and the capital flows that may be associated with the change in the capital stock. Exploring the link between real investment and capital flows can bring out the value of waiting before implementing a decision to invest, and therefore provide an alternative explanation for the sudden movements in capital flows.

While one cannot draw a precise link between the capital inflows and domestic investment, a significant fraction of their investment was financed by foreign capital. For example, for the developing countries in Asia, investment rose from 29 percent of GDP in 1983-90 to 33 percent of GDP in 1991-96, and from 28 percent of GDP to 32 percent of GDP over the same period for the four newly industrialized Asian economies (Table A44, I.M.F. World Economic Outlook, October 1997). Over this same period, there were substantial capital inflows into many of these countries.

The Asian crisis thus highlights an important role for foreign borrowing in facilitating the expansion of business fixed investment, especially real estate. Thus it would appear useful to explore the extension of theories of real estate investment to a model of capital flows in an open economy. In particular, the model of Grenadier (1996) shows how a game-theoretic approach to the exercise of options can be useful in explaining certain aspects of investment decisions. In particular, international capital movements share many features with real state investment in that they do not always take place smoothly and continuously, but rather are often subject to sharp bursts of inflows and outflows.

The model developed here relaxes the assumption of indivisible investment in Grenadier (1996) by allowing a variable investment level and external borrowing so as to adapt the model to the situation of an open economy. Both the case of monopoly and that of Cournot competition between investors are modeled explicitly and related to the economic fundamentals of the economy where the investment takes place. Imperfect competition is a feature required to capture the strategic interaction of market players, as market share is often cited as an important consideration when investing in a foreign market. Market share would be irrelevant in a perfectly competitive environment. This modified model rationalizes such phenomena as gradual investment, investment booms, and investment during recessions, and it emphasizes the role of sunk costs and uncertainty in determining the timing of investment. It also shows that the correlation between capital flows and the spread 
between the domestic return to capital and the foreign interest rate depends importantly on the source of uncertainty; if the foreign interest rate is stochastic, the correlation is expected to be high, but would be low if the uncertainty affects the domestic rate of return.

The organization of the paper is a follows. Section II reviews the related literature. The following Section develops the model of the real option approach to capital flows. Section IV presents the results corresponding to the case of domestic exogenous shocks and Section $\mathrm{V}$ those corresponding to exogenous shocks to the borrowing rate. Section describes the relationship between the interest rate spread and capital flows. Section concludes.

\section{Related Literature}

Besides the work of Grenadier cited above, there are only a few examples in the literature that address the strategic aspect of the investment decision, which include Kulatilaka and Perotti (1992), Lambrecht and Perraudin (2003) and Smets (1993). Kulatilaka and Perotti study the case of strategic investment in a two-period duopoly model with certain fixed costs but uncertain variable costs. They consider both the Cournot and the Stackelberg cases. Lambrecht and Perraudin show that the value of the option to invest by a single firm is reduced drastically when there exists the possibility of strategic entry by competing firms. Smets uses a duopolistic competition setup similar to that of Grenadier, and hence, similar to that used in this paper, to analyze the strategic decision of firms to switch from exporting to foreign direct investment as a means of exploiting profits in a foreign market, which arises from lower variable labor costs in the foreign country. In Smets' model, there are two equilibria. In the first one, firms invest jointly while in the second one, foreign direct investment proceeds sequentially. A common feature of these models is that firms and agents decisions can be modeled as optimal stopping problems. A detailed exposition of the related theory can be found in Dutta and Rustichini (1993) and Lambrecht and Perraudin (1994).

While it does not consider strategic behavior, the work of Kulatilaka and Kogut (1996) is also related. It builds upon earlier work by Dixit (1989) on the persistence of trade deficits as resulting from the decision of exporters to enter a domestic market during a period of exchange rate overvaluation, while keeping the option to withdraw when the exchange rate moves unfavorably. Kulatilaka and Kogut introduced as an alternative to exporting the possibility of shifting production to the domestic economy, 
emphasizing foreign direct investment as the source of hysteresis instead of trade as posed originally by Dixit.

Clearly, there are alternative ways to model investment and capital flows besides the one proposed here. In particular, there is the approach based on asymmetric and incomplete information, as exemplified by Chen and Huang (1995), Chen and Khan (1997), and Cabral (1997), among others. We argue that the approach proposed here has the advantage that there are no asymmetries among investors since each one has access to all the information available and knows how his investment decision affects the domestic return to capital.

\section{The Model}

There are two prospective foreign investors in the world economy. Starting operations in the domestic economy requires spending a considerable amount of resources to gather information about the country's economic and legal conditions. The cost of obtaining this information can be represented by a fixed cost, $I$. After the information has been collected, it is necessary to obtain an operation permit, which we will assume is granted after $\delta$ years, where $\delta$ is an exogenous parameter. Once operations start, the investor rents capital from the world market at a given rate, $r$, and obtains the domestic rate of return, $P$, which is decreasing in the total amount of capital invested in the economy. There are no adjustment costs to changing the stock of capital in any given period. Capital flows in the model are simply captured by the temporal evolution of the stock of capital over time.

We are interested in capturing the idea that first movers have an advantage over late comers, as it appears that market share is an important determinant in business decisions and one of the factors motivating investment in emerging markets. A simple way to model this behavior is to assume that investors are not price takers in the domestic economy: if there is only one active project, the firm behaves as a monopoly. In the case of two active projects, the total amount of capital is the determined in a Cournot equilibrium. Therefore, the advantage of being a first mover is the higher profit obtained as a monopolist. We will refer to the first mover as the Leader and to the late comer as the Follower.

Uncertainty is characterized by an exogenous shock, $X$ that is governed by a geometric brownian motion:

$$
d X=\mu X d t+\sigma X d z
$$


where $\mu$ is the expected growth rate of $X, \sigma$ is sometimes referred to as the instantaneous variance of $X$, and $d z$ is the increment of a standard Wiener Process. It is assumed that $\mu$ and $\sigma$ are constants. Under this assumption, $X$ is lognormally distributed with mean $\left(\mu-1 / 2 \sigma^{2}\right)$ and variance $\sigma^{2} t$.

It remains to specify where the uncertainty comes from. From the point of view of an investor, there are two possible sources of uncertainty that can affect profits, and hence, his investment decisions. Firstly, there exists uncertainty related to the country itself that affects the domestic return on the project. Secondly, fluctuations in the borrowing terms on the world capital market will also affect profits. Clearly, uncertainty related to both domestic and world economic and political conditions are very important. To keep the analysis simple, we restrict the analysis to the two extreme cases of domestic and foreign uncertainty, which we characterized in Assumptions 1 and 2 below, respectively.

Assumption 1 (Domestic Uncertainty) The investors can borrow capital from abroad at the risk free rate, $r$, and the domestic rate of return is stochastic and given by

$$
P(t)=X(t)[Q(t)]^{\theta},
$$

where $\mathrm{P}$ is the gross domestic return to one unit of capital, $\mathrm{Q}$ is the total capital supplied in the domestic economy, $\theta \in(-1,0)$ is the elasticity of the rate of return with respect to capital and $X$, defined above, is a multiplicative shock.

Under Assumption 1, returns in the domestic economy exhibit decreasing returns to scale in total capital stock, $\operatorname{since} \operatorname{sign}(\partial P / \partial Q) \operatorname{sign}(\theta)<0$. As $\theta \uparrow 0$, returns to scale become constant. Also, the domestic return is an increasing function of the shock, $X$. The next assumption characterizes the case in which there is uncertainty surrounding the cost of borrowing.

Assumption 2 (Foreign Uncertainty) The domestic return to capital is given by

$$
P(t)=[Q(t)]^{\theta},
$$

while the borrowing rate from abroad is given by

$$
r_{t}=R X_{t} \text {, }
$$

where $R>0$ is a constant, and $X$ has been defined above. 
In either case, the main problem facing investors is to decide when is the right time to start investing in the domestic economy, as profits must be high enough to cover the initial sunk costs. This decision can be decomposed in two related problems. First, when is the right time to start investing and to become the Leader, provided no one has entered the market yet? Second, once there is a Leader in the market, when is optimal to be a Follower. Answering these questions require a two-step strategy: we must first solve the Follower's problem and then proceed to solve the Leader's problem, as the latter depends on the former. The next two sections analyze these problems when the domestic rate of return and the borrowing rate are uncertain respectively.

\section{Uncertain Domestic Rate of Return}

In this section, we study the investment decision of the Follower and the Leader when the domestic rate of return is subject to exogenous shocks. This requires deriving profits under both monopoly and Cournot competition as they are needed to determine the optimal strategies of the Follower and the Leader. A simple variable transformation allow us to translate the results obtained by Grenadier (1996) to our model, and explain different patterns of foreign direct investment as the result of investors' strategic behavior.

\section{A. Monopoly}

In this case only the Leader is active in the domestic economy. At time $t$, profits $\pi^{L}$ are given by

$$
\begin{aligned}
\pi_{t}^{L} & =P_{t} Q_{t}-r Q_{t} \\
& =X_{t} Q_{t}^{\theta+1}-r Q_{t} .
\end{aligned}
$$

Profit maximization yields the following expressions for the amount of capital invested, the domestic return and profits:

$$
\begin{gathered}
Q_{t}=\left(\frac{1+\theta}{r}\right)^{\gamma} X_{t}^{\gamma} \\
P_{t}=\frac{r}{1+\theta},
\end{gathered}
$$




$$
\pi^{L}=K_{1} X_{t}^{\gamma}
$$

where $\gamma=-1 / \theta$ and $K_{1}=-\theta\left(\frac{1+\theta}{r}\right)^{\gamma-1}>0$. It can be observed that the amount of capital is positively correlated with the exogenous shock $X$, since $\operatorname{sign}\left(\partial Q^{\prime} \partial X\right) \operatorname{sign}(\gamma)>0$. Therefore, positive shocks are correlated with increases in the capital stock.

From equation (4) it is clear that profits vary stochastically, as they are a function of the random disturbance term, $X$, and they vary inversely with the foreign interest rate, as $\partial K_{1} / \partial r<0$. However, because there are assumed to be no adjustment costs, it follows that the monopolist always varies his capital stock optimally in response to shocks and thereby maintains the domestic rate of return, $P$, at a fixed level for a given $r$, as shown in equation (3). Consequently, the interest rate spread, $P-r$, is also constant and is equal to $-r \theta^{\prime}(1+\theta)>0$

\section{B. Cournot competition}

When the Follower enters the market, equilibrium is a result of Cournot competition. In this case, the instantaneous profits are given by

$$
\pi_{t}^{i}=X_{t} Q_{t}^{\theta} Q_{t}^{i}-r Q_{t}^{i}
$$

for $i=L, F$, where $Q_{t}=Q_{t}^{L}+Q_{t}^{F}$. Profit maximization yields the following first order conditions

$$
\theta X_{t} Q_{t}^{\theta-1} Q_{t}^{i}+X_{t} Q_{t}^{\theta}=r \quad i=L, F
$$

Adding up both first-order conditions and taking into account that in equilibrium $Q_{t}^{L}=Q_{t}^{F}$, yields the following relationships:

$$
\begin{gathered}
Q_{t}=\left(\frac{2+\theta}{2 r}\right)^{\gamma} X_{t}^{\gamma} \\
Q_{t}^{L}=Q_{t}^{F}=Q_{t} / 2 \\
P_{t}=\left(\frac{2 r}{2+\theta}\right) \\
\pi_{t}^{i}=K_{2} X_{t}^{\gamma} \quad i=L, F
\end{gathered}
$$


where $\gamma$ was defined above and the constant $K_{2}$ is given by

$$
K_{2}=\frac{1}{2}\left(\frac{-\theta r}{2+\theta}\right)\left(\frac{2+\theta}{2 r}\right)^{r}
$$

Similar to the case of monopoly, $K_{2}$ is a decreasing function of $r$, implying that ceteris paribus, an increase in the cost of borrowing results in lower net profits. Again, the domestic rate of return to capital, $P$, is constant and the interest rate spread is equal to $-\theta r /(2+\theta)$, which is lower than the monopoly spread. With Cournot competition, for any given value of $X$, the capital stock is larger than under monopoly while the domestic return is smaller. In general, in both regimes there is no correlation between the capital stock level and the interest rate spread. They are negatively correlated only when the regime changes. For example, when the Follower enters the market, the capital stock increases as the spread falls.

We proceed to show that this model is equivalent to Grenadier's by analyzing first the Follower's strategy and then the Leader's strategy.

\section{Follower's strategy}

Once the Leader has already invested in the domestic economy, it is necessary to find the trigger value, $X_{F}$, of the domestic return that makes it attractive to exercise the option to invest in the domestic economy. The value of being the Follower is equal to the amount of capital, $I$, owned by the investor and the option to start the project, with the value of this option denoted by $W(X)$. Standard arguments show that $W(X)$ must be the solution of the following second-order differential equation:

$$
\frac{1}{2} \sigma^{2} X^{2} W^{\prime \prime}(X)+\mu X W^{\prime}(X)-r W(X)=0 .
$$

However, $W(X)$ can also be expressed in terms of $Y$ instead of $X$ because, as noted above, there is a one-to-one relationship between these variables. In this case, the option to invest in the domestic economy will be given by the solution $W(Y)$ of :

$$
\frac{1}{2} \sigma^{2} Y^{2} W^{\prime \prime}(X)+\mu^{\prime} Y W^{\prime}(Y)-r W(X)=0,
$$

where application of Ito's lemma to $Y=X^{\gamma}$ shows that $Y$ is also a geometric brownian motion that satisfies: 


$$
d Y=\mu^{\prime} Y d t+\sigma^{\prime} Y d z
$$

with the parameters $\mu^{\prime}$ and $\sigma^{\prime}$ are defined by:

$$
\begin{gathered}
\mu^{\prime}=\gamma \mu+\frac{1}{2} \gamma(\gamma-1) \sigma^{2}, \\
\sigma^{\prime}=\gamma \sigma .
\end{gathered}
$$

Inspection of equations (4) and (5) shows that net profits are linear functions of $Y$ both in the monopoly case and the Cournot competition case:

$$
\begin{aligned}
d \pi & =K d Y \\
& =\left(K \mu^{\prime} Y d t+K \sigma^{\prime} Y d z\right) \\
& =\left(\mu^{\prime} \pi d t+\sigma^{\prime} \pi d z\right)
\end{aligned}
$$

Therefore, we can reinterpret the parameters $\mu^{\prime}$ and $\sigma^{\prime}$ as the expected growth rate and the instantaneous variance of profits net of the borrowing costs respectively. The expected payoff from investing at time $t$ is given by

$$
\begin{aligned}
\Pi_{t} & =\mathrm{E} \int^{\infty} \pi_{s} e^{-r(s-1)} d s \\
& =\frac{\pi_{t}}{r-\mu^{\prime}}
\end{aligned}
$$

Clearly, we require the following assumption:

Assumption $3 \mu^{\prime}<r$

The general solution $W(Y)$ of equation (6) is given by

$$
W(Y)=A Y^{\beta}+B Y^{\beta_{1}}
$$

where $\beta$ and $\beta_{1}$ are the positive and negative solutions respectively of the quadratic equation:

$$
\frac{1}{2} \sigma^{\prime 2} \eta(\eta-1)+\mu^{\prime} \eta-r=0
$$

Because we impose the condition that the value to invest is null when $Y=0$, the 
constant $B$ must be equal to zero, so that the solution reduces to:

$$
W(Y)=A Y^{\beta}
$$

where

$$
\beta=\frac{1}{2}-\frac{\mu^{\prime}}{\sigma^{\prime 2}}+\sqrt{\left(\frac{\mu^{\prime}}{\sigma^{\prime 2}}-\frac{1}{2}\right)^{2}+\frac{2 r}{\sigma^{\prime 2}}} .
$$

The value of the constant, $A$, as well as the value of $Y_{F}$ must be determined from the boundary conditions:

$$
\begin{gathered}
W\left(Y_{F}\right)=\frac{e^{-\left(r-\mu^{\prime}\right) \delta}}{r-\mu^{\prime}} K_{2} Y_{F}-I, \\
W\left(Y_{F}\right)=\frac{e^{-\left(r-\mu^{\prime}\right) \delta}}{r-\mu^{\prime}} K_{2} .
\end{gathered}
$$

Condition (8) is the value matching condition, that simply states that at the trigger value $Y_{F}$, the value of the option must be equal to the discounted cash flow obtained from exercising it. Equation (9) is the smooth pasting condition which is necessary to assure maximization of the option to invest. The left-hand side is the marginal value of waiting and the right-hand side is the marginal value of the investment.

\section{Optimal strategy of the Follower}

We can find an expression for the value of the option to invest using equations (7), (8) and (9) to determine both the constant, $A$ and the trigger value, $Y_{F}$ :

$$
W(Y)= \begin{cases}\frac{1}{\beta-1}\left(\frac{Y}{Y_{F}}\right)^{\beta} & \text { if } Y<Y_{F} \\ \frac{e^{-\left(r-\mu^{\prime}\right) \delta}}{r-\mu^{\prime}} K_{2} Y-1 & \text { if } Y \geq Y_{F}\end{cases}
$$

where the trigger value is given by

$$
Y_{F}=\left(\frac{\beta I}{\beta-1}\right)\left(\frac{r-\mu^{\prime}}{K_{2}}\right) e^{\left(r-\mu^{\prime}\right) \delta}
$$

When stated in terms of $X$, the trigger value is $X_{F}=Y_{F}^{1 / \gamma}$. Being the follower thus has a value equal to: 


$$
F(Y)=I+W(Y)
$$

The Follower will enter the market only when there is a wedge between the present value of the decision and the sunk cost $I$, which can be seen from the fact that $F\left(Y_{F}\right)=I \beta^{\prime}(\beta-1)$. We obtain the following proposition, analogous to Proposition 1 in Grenadier (1996):

Proposition 1. Conditional on the Leader having committed to operate in the country, the optimal Follower strategy is to pay the sunk cost 1 and enter the domestic market the first moment that $X_{t}$ equals or exceeds the trigger value $X_{F}$, that is the optimal entry time of the Follower, $T_{F}$ is given by

$$
T_{F}=\inf \left\{t \geq 0: X_{t} \geq\left[\left(\frac{\beta I}{\beta-1}\right)\left(\frac{r-u^{\prime}}{K^{2}}\right) e^{\left(r-u^{\prime}\right) \delta}\right]^{1 / \gamma}\right\} .
$$

The expected optimal entry time of the follower, $T_{F}$, increases in $r$ as borrowing becomes more expensive, because higher domestic returns are required so that the present discounted value of the project, which is decreasing in $r$, is enough to cover the fixed cost, $I$. For the same reason, an increase in the latter increases the expected entry time. If the time to obtain an operating permit, $\delta$, lengthens, the expected entry time also increases since it takes longer to start operating in the domestic country and recover the sunk cost. In contrast, when $\sigma$ increases and domestic return becomes more volatile, the expected entry time decreases because the effective drift component, increases. The latter is equivalent to the deterministic growth rate of the domestic return, so a higher value makes the investment project more attractive. In addition, we can interpret as the opportunity cost of postponing operations. As this cost decreases, the optimal stopping time $T_{F}$ decreases, leading to a smaller delay. In the limit case, $T_{F} \downarrow 0$ as $\mu^{\prime} \uparrow r$ since it is optimal to start operations immediately when the opportunity cost is null.

\section{Leader's strategy}

As noted above, the Leader's strategy is complicated by the fact that it must take account of the Follower's behavior. Assume that in the year $t$ the Leader's is still $\tau$ years from obtaining the operation permit and define $L(Y, \tau)$ as the value of the Leader's project at that specific time. If $Y \geq Y_{F}$, the value of the Leader's project is equal to 


$$
\frac{e^{-\left(r-u^{\prime}\right) \tau}}{r-u^{\prime}} K_{1} Y+\frac{e^{-\left(r-u^{\prime}\right) \delta}}{r-u^{\prime}}\left(K_{2}-K_{1}\right) Y
$$

where the first term is the expected discounted present value of holding a monopoly position forever and the second term is the necessary correction once the Follower starts operations.

If $X<X_{F}$, then the Follower will not enter the market until year $T_{F}$, where $T_{F}$ is the first time in which $X>X_{F}$. Grenadier shows that the Leader's payoff is equivalent to the payoff of the following portfolio:

1) Purchase a call option on an asset that pays a perpetual dividend rate of $K_{1} Y$, with zero exercise price and fixed expiration date of $\tau$.

2) Purchase a call option on an asset that pays a perpetual dividend rate of $\left(\mathrm{K}_{2}\right.$ $\left.K_{1}\right) Y$, with zero exercise price and a stochastic expiration date $T_{F}+\delta$

Notice that although our setup allows for a variable capital stock, our assumptions reduce the problem to a setup similar to that of Grenadier's, where his constants $D(2)<D(1)$ have been replaced by our constants $K_{2}<K_{1}$ respectively, provided that the original stochastic variable $X$ is replaced by $Y$. Therefore, the solution of $L(Y, \tau)$ is given by

$$
L(Y, \tau)= \begin{cases}\frac{e^{-\left(r-\mu^{\prime}\right) \tau}}{r-u^{\prime}} K_{1} Y+\frac{\beta I}{\beta-1}\left(\frac{K_{2}-K_{1}}{K_{2}}\right)\left(\frac{\gamma}{\gamma_{F}}\right)^{\beta} \quad \text { if } \quad Y<Y_{F} \\ \frac{e^{-\left(r-\mu^{\prime}\right) \tau}}{r-u^{\prime}} K_{1} Y+\frac{e^{-\left(r-\mu^{\prime}\right) \delta}}{r-\mu^{\prime}}\left(K_{2}-K_{1}\right) Y \quad \text { if } \quad Y \geq Y_{F}\end{cases}
$$

Thus all the results from Grenadier (1996) follow through. In particular, we have an analog of his Proposition 2 which establishes when it is more valuable to be the Leader or the Follower, and that drives all the results with respect to the investment strategies:

Proposition 2. Assume that the Leader is just starting to gather the information after paying the sunk cost, that is $\tau=\delta$. Then there exists a unique point $Y_{L} \in\left(0, Y_{F}\right)$ with the following properties:

a) $L(Y, \delta)-I<W(Y) \quad$ if $Y<Y_{L}$

b) $L(Y, \delta)-I=W(Y)$ if $Y=Y_{L}$ 
c) $L(Y, \delta)-I>W(Y)$ if $Y_{L}<Y<Y_{F}$

d) $L(Y, \delta)-I=W(Y)$ if $Y \geq Y_{F}$

Proof: See Grenadier (1996).

Clearly, there is one $X_{L}$ such that $Y_{L}=X_{L}^{\gamma}$, so that we can either refer to trigger points with respect to the original geometric brownian motion or the modified one.

\section{Hysteresis and Sequential Development}

In this section we illustrate graphically the timing of the investment as well as the evolution of the capital stock and therefore capital flows. In our model with only two investors, sequential development is the process in which one investor starts to invest in the domestic economy, and then only after some time elapses the second investor takes the same decision. This investment pattern corresponds to one of the two possible subgame perfect equilibria of the model while the other equilibrium corresponds to the process of simultaneous investment, as in Grenadier (1996). In the context of the domestic economy where the stochastic shock $X$ is positively correlated with the domestic return in the country, the higher $X$ is, the better are the domestic economic conditions. Proposition shows that there are two important points, $X_{L}$ and $X_{F}$, satisfying $X_{L}<X_{F}$, which summarize the economic conditions required to have either one, two or no investor operating in the country. Sequential investment occurs only if the country's initial economic conditions are lower than $X_{F}$ and is characterized in the following proposition.

Equilibrium with sequential investment: Assume that the initial shock value satisfies $X_{o}<X_{F}$. If your competitor has not started his project, then start the project when $X_{t} \geq X_{L}$ for the first time. If the competitor is already in the market, wait until $X_{t} \geq X_{F}$ to start your project.

If domestic conditions are lower than the value associated with $X_{L}$, no investor would start a project in the country economy. Why? Starting a project requires paying a sunk cost of $I$ and because of the uncertainty surrounding the domestic rate of return, waiting to invest has an economic value. Therefore, it is possible that during long periods no new projects are started, despite a positive trend of the country's economic conditions. This is the so called hysteresis effect (Dixit, 1992). When the level $X_{L}$ is reached, then one of the investors starts his project and operates it enjoying monopoly profits. For economic conditions between $X_{L}$ and $X_{F}$, it is not profitable for the remaining investor to follow. Figure 1 illustrates these two 
Figure 1. Entry times of the Leader and the Follower

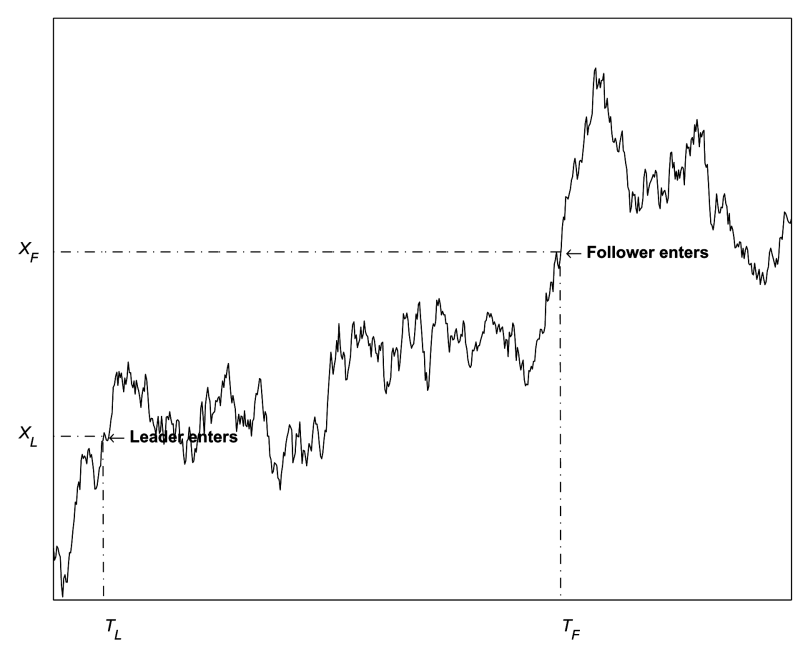

threshold values of $X$. As the exogenous shock evolves over time, the Leader enters when $X=X_{F}$ for the first time at $t=T_{L}$ The Follower does not invest until the economic conditions reach a new higher level associated with $X_{F}$.

Figure 2 illustrates how the capital stock evolves over time. Before time $T_{L}+\delta$, the capital stock is zero. Afterwards, it jumps to an amount equal to $Q_{T_{L}+\delta}=\left(1+\theta^{\prime} r\right)^{\gamma} X_{T_{L}+\delta}^{\gamma}$ and varies continuously as the monopolist adjusts the capital stock to keep the optimal markup. This process continues until time $T_{L}+\delta$, the point at which the

Figure 2. Capital stock in the domestic economy

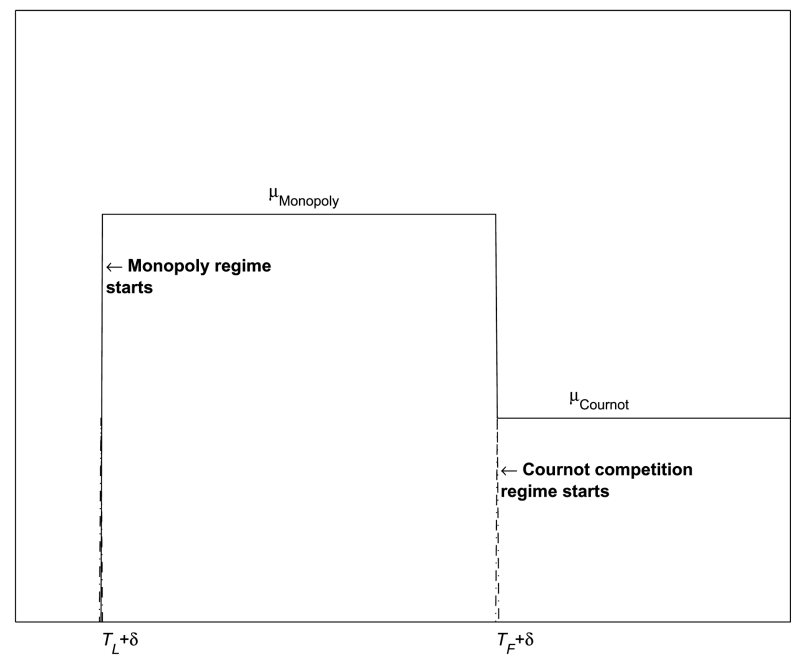


Figure 3. Markup in the domestic economy

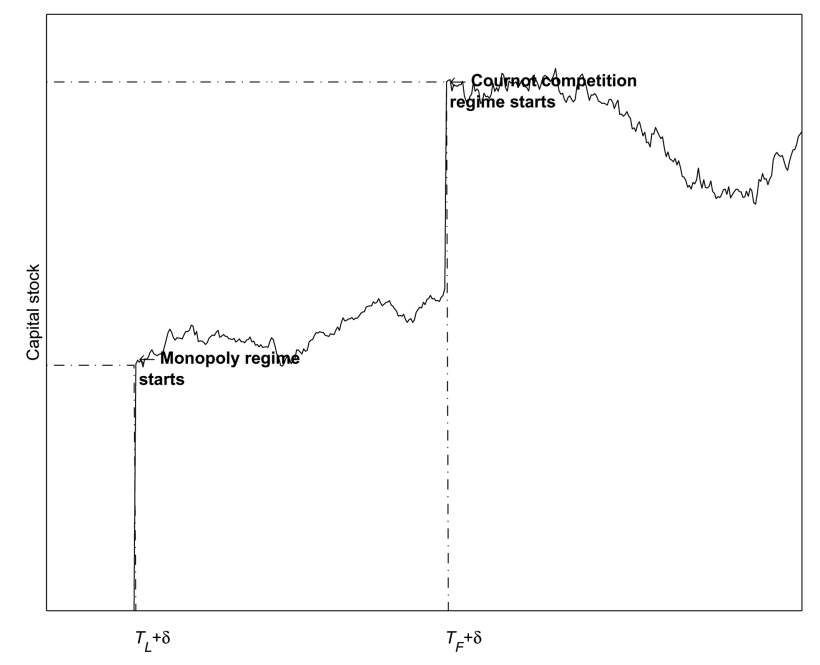

Leader and the Follower engage in Cournot competition. At that time, the total capital stock jumps from $Q_{T_{L}+\delta}$ to $Q_{T_{F}+\delta}=\left(2+\theta^{\prime} 2 r\right)^{\gamma} X_{T_{F}+\delta}^{\gamma}$. Afterwards, the capital stock changes continuously as both duopolists adjust their stocks to maximize profits. Therefore, this model can explains discrete upward jumps of capital inflows. Increased competition at $T_{F}+\delta$ is also associated with a decrease in the domestic interest rate markup, as shown in Figure 3.

\section{E. Investment Booms}

We have already examined what happens in an economy when the initial economic conditions are such that, so it remains to explain what happens when. The proposition below describes the other subgame perfect equilibrium that gives rise to simultaneous entry by both competitors.

Proposition 3. Equilibrium with simultaneous investment or investment boom: Assume that the initial shock value satisfies $X_{o} \geq X_{F}$. Then there exists $X_{J}>X_{F}$ such that the optimal strategy is to start the project at once the moment $X_{t} \leq X_{F}$ or $X_{t} \geq X_{J}$. If the competitor enters first, then enter instantaneously thereafter.

Proof: See Grenadier (1996).

If the shock is in the range corresponding to the interval $\left[X_{F} X_{J}\right]$ the best policy for both investors is inaction. However, once the shock moves outside the interval, 
Figure 4. Investment boom in a period of improving economic fundamentals

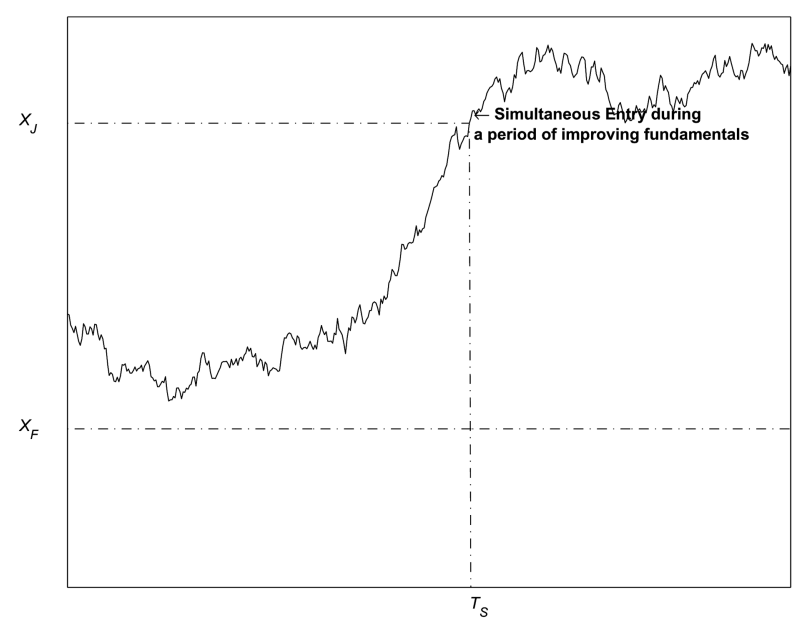

it is in the interests of both investors to start the projects straight away. Therefore, there are two possible cases of simultaneous entry, one related to improving economic fundamentals, as shown in Figure 4. For any given $X>X_{F}$, the equilibrium strategy is to enter immediately whenever $\hat{X}$ is reached, since the value of being the Leader is greater than value of being the Follower. In particular, there is a value $X_{J}$ such that it maximizes the value of both competitors is maximized when they enter simultaneously. Therefore, both investors enter at the same time when $X$ reaches

Figure 5. Investment boom in a period of declining economic fundamentals.

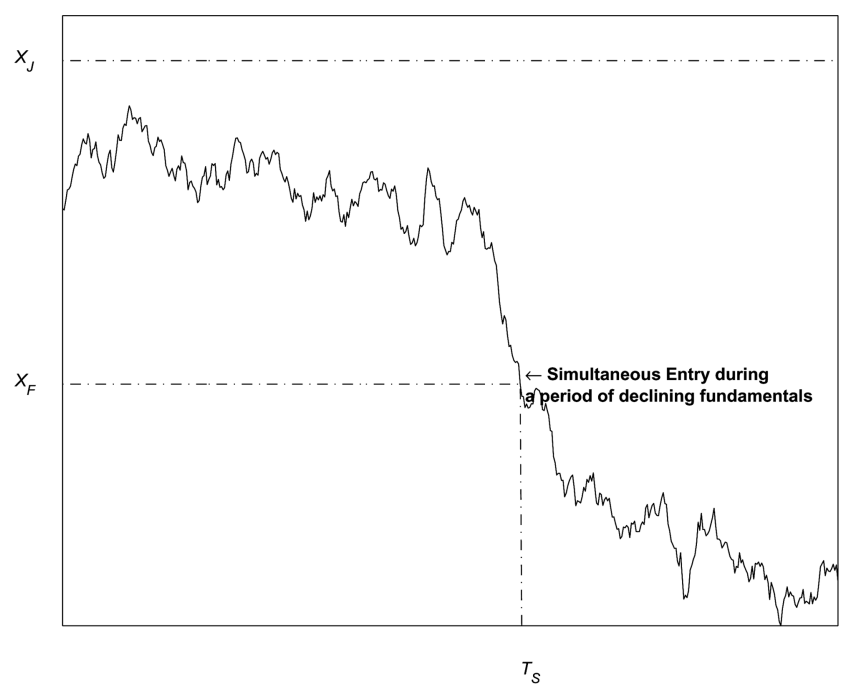


the value $X_{J}$ as long as $X$ has not fallen below $X_{F}$.

The other case of simultaneous entry is related to a deterioration of the economic fundamentals, as shown in Figure 5. This last case rationalizes what it would otherwise seem to be the irrational start of new projects when the economy starts to slowdown. The rationale behind entry when economic prospects are deteriorating is as follows. From Proposition (), it is more valuable to be the Leader than the Follower when $Y \in\left[Y_{L}, Y_{F}\right]$, or respectively, when $X \in\left[X_{L}, X_{F}\right]$. Therefore, as soon as the value of is less than $X_{F}$, both investors enter simultaneously.

Whether investment follows a sequential process or a boom depends on the initial conditions, summarized by the value of the exogenous shock at $t=0, X_{0}$. If $X_{0}$ is below $X_{F}$, we would observe sequential investment. However, it could be the case that structural reforms, such as the removal of capital controls or the liberalization of the financial sector, improve the profitability of investment, shifting to a value in the range $\left[X_{F} X_{J}\right]$. In this case, investment would be characterized by an initial period of inaction followed by a boom.

\section{Uncertain Borrowing Rate}

In this section we analyze the case in which the exogenous shock affect the borrowing cost. We will prove that this case is analogous to that of a stochastic domestic return and that all the results derived previously hold in this setup. Under Assumption 2 and normalizing $R \equiv 1$, it is not difficult to show that in the case of monopoly, the capital stock, profits and the domestic return to capital are given by:

$$
\begin{aligned}
Q_{t} & =\left(\frac{X_{t}}{1+\theta}\right)^{1 / \theta}, \\
P_{t} & =\frac{X_{t}}{1+\theta}, \\
\pi_{t}^{L} & =-\theta(1+\theta)^{-\frac{1+\theta}{\theta}} X_{t}^{\frac{1+\theta}{\theta}}, \\
& =K_{1} Y_{t}^{\omega},
\end{aligned}
$$

where $\omega=\frac{1+\theta}{\theta}<0$. The interest rate spread $P_{t}-r_{t}=-\mathrm{X}_{t} \theta(1+\theta)$ now is variable, although the ratio of the domestic return to the borrowing rate or the markup is always constant and equal to $1 /(1+\theta)$. The relationship between total capital stock 
and the exogenous shock is exactly opposite to that described in the previous section: total capital stock increases when the borrowing rate decreases, a result that we would expect. Also, there is a negative correlation between capital stock and the interest rate spread. This result explains partially the observed negative correlation between the interest rate spread and the amount of capital flows to emerging markets, as documented in Cline and Barnes (1997).

In the case of Cournot competition, capital stock, profits for each investor and the domestic rate of return are given by:

$$
\begin{aligned}
Q_{t} & =\left(\frac{X_{t}}{1+\theta^{\prime 2}}\right)^{1 / \theta}, \\
P_{t} & =\frac{X_{t}}{1+\theta^{\prime 2}}, \\
\pi_{t}^{L} & =-\frac{\theta}{2}\left(1+\frac{\theta}{2}\right)^{-\frac{1+\theta}{\theta}} X_{t}^{\frac{1+\theta}{\theta}}, \\
& =K_{2} Y_{t}^{\omega},
\end{aligned}
$$

Again, capital stock is negatively correlated with both increases in the borrowing rate, as represented by an increase in $X$ and with the interest rate spread. Therefore, all the analysis of the previous case applies here. However, we must recall that $\omega<0$, therefore, the analogous propositions must take into account that if $Y^{*}>Y^{* *} \Rightarrow X^{*}<$ $\mathrm{X}^{* *}$. This implies that the correct ordering of the trigger points, if stated in terms of the original brownian motion, $X$, should be $X_{L}>X_{F}>X_{J}$. This makes sense, since an increase in $X$ reflects a higher borrowing cost, instead of a higher return. It is necessary to reformulate the equilibrium investment strategies as follows.

\section{Equilibrium development strategies}

1) Equilibrium with sequential development: Assume that the initial shock value satisfies $X_{0}>X_{F}$. If your competitor has not started his project, then start the project when $X_{t} \leq X_{L}$ for the first time. If the competitor is already in the market, wait until $X_{t} \leq X_{L}$ to start your project.

2) Equilibrium with simultaneous development: Assume that the initial shock value satisfies $X_{0}<X_{F}$ Then it is possible to show that there exists a trigger value $X_{\mathrm{J}}<X_{F}$ such that the optimal strategy is to start the project at once the moment $X_{t} \geq X_{F}$ or $X_{t} \leq X_{J}$. If the competitor enters first, then enter instantaneously thereafter. 


\section{The Relationship between the Interest Rate Spread and Capital Flows}

Because of imperfect competition, profit maximization by the investors require that they charge a constant markup over their borrowing costs. When the domestic rate of return is stochastic, the Cournot and monopoly markups, $P_{t} / r$, and interest rate spreads, $P_{t}-r$, are given by:

$$
\begin{aligned}
& \text { Monopoly Cournot } \\
& \text { Markup: } 1 /(1+\theta) \quad 2 /(2+\theta) \\
& \text { Spred: } \quad-r \theta^{\prime}(1+\theta) \quad-r \theta^{\prime}(2+\theta)
\end{aligned}
$$

When the borrowing cost is constant the interest rate spread remains constant despite changes in the multiplicative shock that affect the domestic rate of return. But changes in the domestic rate of return do affect the capital stock, $Q$, as it adjusts continuously such that the optimal markup is preserved. In this environment, in which the cost of capital remains fixed, the interest rate spread does not provide information about changes in the capital stock, implying an almost always zero correlation between these two quantities. The only exception is the case in which the regime changes from monopoly to Cournot, that was illustrated in Figures 3 and 4 . We would observe a decrease in the spread and the interest rate markup going hand in hand with an increase in the capital stock. When there is market power and the domestic return is affected by shocks, the interest rate spread provides little information about capital flows.

When uncertainty is driven by shocks to the borrowing rate, profit maximization implies preserving the optimal markup as in the previous case leading to a variable domestic interest rate which is a linear function of the borrowing rate, and hence it generates an interest rate spread perfectly correlated with the borrowing rate as represented by $X$ :

$$
\begin{aligned}
& \text { Monopoly Cournot } \\
& \text { Markup: } \quad 1 /(1+\theta) \quad 2 /(2+\theta) \\
& \text { Spred: } \quad-X \theta^{\prime}(1+\theta) \quad-X \theta^{\prime}(2+\theta)
\end{aligned}
$$

In this case we observe a negative correlation between capital flows and the interest rate spread, a stylized fact of foreign investment. A literal interpretation of the model would interpret this phenomenon as an evidence of the importance of external shocks to the borrowing costs faced by investors. 


\section{Concluding Remarks}

This paper has shown that some stylized facts of capital flows can be rationalized in an irreversible investment framework, where firs movers can benefit more by obtaining monopoly profits investing capital in a small country. The stylized facts include the following: foreign direct investment can either proceed at a gradual pace or there can be a burst in activity, depending on what the economic fundamentals are; new investments can take place despite a declining trend in fundamentals; and finally capital flows and interest rate spreads do not need to be correlated. Moreover, such correlation depends on whether economic fundamentals are being affected by domestic or foreign shocks.

Though much attention has been paid to entry strategies and some simple results have been obtained, the model is mute with respect to the possibility of exit. In the model, capital flows follow a continuous process characterized by discrete upward jumps, which seem to characterize the observed pattern of capital flows. The introduction of exit decisions would introduce also discrete downward jumps in the capital stock, that can be interpreted as drastic capital outflows.

\section{Acknowledgments}

We have benefited from comments by Peter Isard, Andrei Kirilenko, Charles Kramer, and Athanasios Vamvakidis. The views reflected here are only those of the authors and do not necessarily reflect those of the International Monetary Fund.

Received 27 January 2004, Accepted 3 July 2006

\section{References}

Cabral, L. 1997. Entry mistakes. CEPR Discussion paper 1729, London.

Caplin, A. and J. Leahy. 1996. Miracle on 6th Avenue. American Economic Review.

Chen, Z. and H. Huang. 1995. Investment Trap. Mimeo. International Monetary Fund and London School of Economics.

Chen, Z. and M. Khan. 1997. Patterns of capital flows to emerging markets: a theoretical perspective. Working paper 97-13. International Monetary Fund, Washington, D.C. Cline, W.R. and K.J.S. Barnes. 1997. Spreads and risk in emerging markets lending. Institute of International Finance Research Paper 97-1, Washington, D.C.

Dixit, A. 1989. Hysteresis, import penetration and exchange rate pass-trough. Quarterly 
Journal of Economics 104, 205-228.

Dixit, A. 1992. Investment and hysteresis. Journal of Economic Perspectives 6, 107-132.

Dixit, A. 1993. The art of smooth pasting. Harwood Press.

Dixit, A. and R. Pindyck. 1994. Investment under uncertainty. Princeton University Press, NJ, U.S.A.

Dutta, P.K. and A. Rustichini. 1993. A theory of stopping time games with applications to product innovation and asset sales. Economic Theory 3, 743-763.

Dygvig, P.H. and J.F. Zender. 1991. Capital structure and dividend irrelevance with asymmetric information. Review of Economic Studies 4, 201-219.

Grenadier, S.R. 1995. The persistence of real estate cycles. Journal of Real Estate Finance and Economics 10, 95-119.

Grenadier, S.R. 1996. The strategic exercise of options: development cascades and overbuilding in real estate markets. Journal of Finance 51, 1653-1679.

Kulatilaka, N. and B. Kogut. 1996. Direct investment, hysteresis and real exchange rate volatility. Journal of the Japanese and International Economies 10, 12-36.

Kulatilaka, N. and E. Perotti. 1992. Strategic investment timing under uncertainty. Discussion paper 145, London School of Economics, Financial Markets Group.

Lambrecht, B. and W. Perraudin. 1994. Option games. DAE Working Paper No. 9414. Cambridge University.

Lambrecht, B. and W. Perraudin. 2003. Real options and preemption under incomplete information. Journal of Economic Dynamics and Control 27, 619-643.

Smets, F.R. 1993. Exporting vs. foreign direct investment: the effect of uncertainty, irreversibilities and strategic interactions. Unpublished Ph.D. dissertation, Yale University. 